\title{
Similarities and differences in interactions of thyroid stimulating and blocking autoantibodies with the TSH receptor
}

\author{
Ricardo Núñez Miguel, Jane Sanders, Paul Sanders, Stuart Young, Jill Clark, \\ Katarzyna Kabelis, Jane Wilmot, Michele Evans, Emma Roberts, Xiaoling Hu, \\ Jadwiga Furmaniak and Bernard Rees Smith
}

FIRS Laboratories, RSR Ltd, Parc Ty Glas, Llanishen, Cardiff CF14 5DU, UK

(Correspondence should be addressed to B Rees Smith; Email: firs@ rsrltd.eclipse.co.uk)

\begin{abstract}
Binding of a new thyroid-stimulating human monoclonal autoantibody (MAb) K1-18 to the TSH receptor (TSHR) leucinerich domain (LRD) was predicted using charge-charge interaction mapping based on unique complementarities between the TSHR in interactions with the thyroid-stimulating human MAb M22 or the thyroid-blocking human MAb K1-70. The interactions of K1-18 with the TSHR LRD were compared with the interactions in the crystal structures of the M22-TSHR LRD and K1-70-TSHR LRD complexes. Furthermore, the predicted position of K1-18 on the TSHR was validated by the effects of TSHR mutations on the stimulating activity of K1-18. A similar approach was adopted for predicting binding of a mouse thyroid-blocking MAb RSR-B2 to the TSHR. K1-18 is predicted to bind to the TSHR LRD in a similar way as TSH and M22. The binding analysis suggests that K1-18 light chain (LC) mimics binding of the TSH- $\alpha$ chain and the heavy chain $(\mathrm{HC})$ mimics binding of the TSH- $\beta$ chain. By contrast, M22 HC mimics the interactions of TSH- $\alpha$ while M22 LC mimics TSH- $\beta$ in interactions with the TSHR. The observed interactions in the M22-TSHR LRD and K1-70-TSHR LRD complexes (crystal structures) with TSH-TSHR LRD (comparative model) and K1-18-TSHR LRD (predictive binding) suggest that $\mathrm{K} 1-18$ and $\mathrm{M} 22$ interactions with the receptor may reflect interaction of thyroid-stimulating autoantibodies in general. Furthermore, K1-70 and RSR-B2 interactions with the TSHR LRD may reflect binding of TSHR-blocking autoantibodies in general. Interactions involving the C-terminal part of the TSHR LRD may be important for receptor activation by autoantibodies.
\end{abstract}

Journal of Molecular Endocrinology (2012) 49, 137-151

\section{Introduction}

K1-18 is a TSH receptor (TSHR) human monoclonal autoantibody (MAb; IgG1/kappa) with the ability to stimulate cAMP production in TSHR-transfected $\mathrm{CHO}$ cells and to inhibit TSH binding to the receptor at nanogram per millilitre concentrations (Rees Smith et al. 2009, Evans et al. 2010, Sanders et al. 2010). K1-18 has high binding affinity for the TSHR of $\sim 6.7 \times 10^{9} \mathrm{l} / \mathrm{mol}$, and the characteristics of K1-18 fulfil the criteria set out for human TSHR MAbs (McLachlan \& Rapoport 1996). To date, the crystal structures of a thyroidstimulating human MAb M22 (1.65 A resolution; Sanders et al. 2004) and a thyroid-blocking human MAb K1-70 (2.22 A resolution; Sanders et al. 2011) have been described. In addition, a mouse TSHR MAb (RSR-B2) with potent TSH-binding inhibiting and TSHR antagonist activities has also been crystallised (3.30 A resolution; Sanders et al. 2005). TSHR amino acids involved in the interactions of RSR-B2 were identified in a series of experiments with mutated TSHR (Sanders et al. 2006, 2010). The structures of the TSHR leucine-rich domain (LRD) in complex with M22

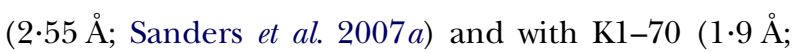
Sanders et al. 2011) provided molecular details of the interactions of M22 and K1-70 with the receptor. To study the interactions of TSH with the TSHR, a comparative model of a TSH-TSHR LRD complex has been produced using the crystal structures of M22TSHR LRD (Sanders et al. 2007a) and FSH-FSH receptor (FSHR; Fan \& Hendrickson 2005) complexes to model the binding arrangements between TSH and the TSHR (Núñez Miguel et al. 2008).

We now describe the crystal structure of K1-18 Fab solved at $1.65 \AA$ resolution. The K1-18 structure was then compared with the structures of the thyroidstimulating human MAb M22 (Sanders et al. 2004) and the thyroid-blocking human MAb K1-70 (Sanders et al. 2011). Furthermore, the mouse MAb RSR-B2 that has the characteristics of human thyroid-blocking autoantibodies (Sanders et al. 2006) was included in the study. In particular, features of the electrostatic potential surfaces of the four MAbs were studied. Binding of K1-18 to the TSHR LRD was then predicted using charge-charge interaction mapping based on unique complementarities between the 
TSHR LRD in interaction with the thyroid-stimulating human MAb M22 (Sanders et al. 2007a) or the thyroid-blocking human MAb K1-70 (Sanders et al. 2011). The predicted binding of K1-18 to the TSHR LRD was validated by the effects of TSHR mutations on the stimulating activity of K1-18. A similar approach has also been used to predict the relative position of the thyroid-blocking mouse MAb RSR-B2 on the TSHR.

\section{Materials and methods}

\section{Preparation of K1-18 Fab}

K1-18 IgG was prepared from heterohybridoma culture supernatants using protein A affinity chromatography on MabSelect (GE Healthcare, Little Chalfont, UK) according to the manufacturer's instructions. The purified IgG was treated with mercuripapain (SigmaAldrich) at an enzyme/protein (w/w) ratio of 1:300, EDTA at a final concentration of $2 \mathrm{mmol} / \mathrm{l}$ and L-cysteine at a final concentration of $1 \mathrm{mmol} / \mathrm{l}$ for $2 \mathrm{~h}$ at $37^{\circ} \mathrm{C}$. The reaction was terminated by addition of $50 \mathrm{mmol} / \mathrm{l}$ iodoacetamide in $2 \mathrm{mmol} / \mathrm{l}$ Tris- $\mathrm{HCl}$ ( $\mathrm{pH} \mathrm{8.3)} \mathrm{for} 30 \mathrm{~min}$ at room temperature. The digest was passed through a MabSelect column to remove any intact IgG or Fc from the Fab preparation. K1-18 Fab was dialysed into PBS $(137 \mathrm{mmol} / 1 \mathrm{NaCl}, 8 \cdot 1 \mathrm{mmol} / \mathrm{l}$ $\mathrm{NaHPO}_{4}, 2.7 \mathrm{mmol} / \mathrm{l} \mathrm{KCl}, 1.47 \mathrm{mmol} / 1 \mathrm{KH}_{2} \mathrm{PO}_{4}$, $\mathrm{pH} 7 \cdot 4$ ) containing $0 \cdot 2 \mathrm{~g} / 1$ sodium azide and concentrated to $8.0 \mathrm{mg} / \mathrm{ml}$ using $20 \mathrm{ml} 9 \mathrm{kDa}$ MWCO iCON concentrators (Thermo Scientific, Cramlington, UK). The K1-18 Fab was further purified on a preparative Superdex 75 column using an AKTA platform (GE Healthcare), the peak fractions were pooled and concentrated to $9 \cdot 3 \mathrm{mg} / \mathrm{ml}$ using iCON concentrators. The final K1-18 Fab was analysed by SDS-PAGE, sizeexclusion HPLC and for inhibition of TSH-biotin binding to the TSHR (Bolton et al. 1999). For crystallisation trials the K1-18 Fab was buffer exchanged into $500 \mathrm{mmol} / \mathrm{l} \mathrm{NaCl}, 10 \mathrm{mmol} / \mathrm{l}$ Tris- $\mathrm{HCl}, \mathrm{pH} 7 \cdot 4$ and concentrated to $20 \mathrm{mg} / \mathrm{ml}$ (Evans et al. 2010).

\section{X-ray diffraction and structure determination of K1-18 Fab}

K1-18 crystals were grown using the hanging drop vapour diffusion method in wells containing $15 \%$ PEG $3350,200 \mathrm{mmol} / \mathrm{L} \mathrm{Li}_{2} \mathrm{SO}_{4}$ and $100 \mathrm{mmol} / 1$ Tris- $\mathrm{HCl}$, $\mathrm{pH} 8 \cdot 5$. A single crystal of dimensions $0 \cdot 4 \times 0 \cdot 2 \times 0 \cdot 1 \mathrm{~mm}$ was transferred into an $80 \%$ well solution and $20 \%$ glycerol mix, and flash frozen in liquid nitrogen. The data set was collected using a Rigaku-007HF generator and an R-Axis IV image plate detector and indexed, integrated and scaled using MOSFLM and SCALA (Biofocus, Saffron Walden, UK).

The structure of K1-18 Fab was determined by the molecular replacement method using the PDB coordinates of 1U6A for the light chain (LC) domains and 2VXV for the heavy chain (HC) domains. Molecular replacement was performed using the programme PHASER (Collaborative Computational Project number 4 (CCP4) 1994) and the resulting model refined with tight geometric weights using REFMAC5 (CCP4). Electron density maps calculated after initial refinement were examined using COOT (Emsley et al. 2010) and automatically corrected and rebuilt using BUCCANEER (CCP4). Structural geometry of K1-18 Fab was checked using PROCHECK (Laskowski et al. 1993; CCP4) and RAMPAGE (CCP4) and the residues were numbered in accordance with the Kabat system (Kabat et al. 1991).

\section{Stimulation of cAMP production by K1-18 IgG in $\mathrm{CHO}$ cells expressing wild type or mutated TSHRs}

Point mutations in the TSHR amino acid sequence were introduced using the Flp-In-CHO system (Invitrogen) as described previously (Sanders et al. 2006). The presence of mutation was verified by amino acid sequence analysis (Geneservice Ltd., Cambridge, UK). The ability of K1-18 IgG to stimulate the production of cAMP in CHO cells expressing either WT or mutated TSHRs was tested as described before (Sanders et al. 2006). In these experiments, dilutions of porcine TSH (75 units/mg from RSR; $0 \cdot 01-3 \mathrm{ng} / \mathrm{ml}$ ) and $\mathrm{K1}-18 \mathrm{IgG}$ $(0 \cdot 3-100 \mathrm{ng} / \mathrm{ml})$ in cAMP assay buffer (NaCl-free Hank's Buffered Salts solution containing $1 \mathrm{~g} / 1$ glucose, $20 \mathrm{mmol} / 1 \mathrm{HEPES}, 222 \mathrm{mmol} / 1$ sucrose, $15 \mathrm{~g} / 1 \mathrm{BSA}$ and $0.5 \mathrm{mmol} / 1$ 3-isobutyl-1-methyl xanthine, $\mathrm{pH} 7 \cdot 4$ ) were used and cyclic AMP concentration in the lysates were determined using the Assay Designs Direct Cyclic AMP Correlate-EIA Kit (Enzo Life Sciences (UK) Ltd, Exeter, UK) following the manufacturer's instructions. Relative effects of TSHR mutations were expressed as a percentage of activity observed with WT (i.e.,$+++++ 100 \%$ of WT activity; ++++ , $<100-80 \%$ of WT activity;,$+++<80-60 \%$ of WT activity;,$++<60-40 \%$ of WT activity;,$+<40-20 \%$ of WT activity and $0,<20 \%$ of WT activity).

In all experiments with both WT and mutated TSHRs, cAMP response to different concentrations of TSH was studied alongside the test ligand. TSH response acted as a reference to assess the threedimensional integrity of the mutated TSHR. For example, if the TSHR mutation had no effect on TSH activity relative to the WT but affected the activity of the test ligand, this was classed as an effect. However, TSHR residues that when mutated affected the activity 
of TSH to the same extent as the activity of the test ligand that was not classed as interacting residues as the observed effect may be due to conformational changes in the receptor. The use of TSH as a reference in all experiments was employed in our previous studies and allowed us to compare old and new data sets (Sanders et al. 2006, 2007a,b, 2010, 2011).

\section{Non-bonding interactions and protein-protein complex interface analysis}

Van der Waals interactions between residues and interface surfaces of the complexes were studied using accessible surface areas (ASAs), calculated by the Discovery Studio 2.5.5 programme (DS 2.5.5, Accelrys, Inc., San Diego, CA, USA), which uses an enhanced grid-based numerical algorithm, similar to conventional methods. Interface residues were defined as the residues that possessed an ASA that decreased $(\triangle \mathrm{ASA})$ by more than $1 \AA^{2}$ on complexation (Jones \& Thornton 1996). Electrostatic potential surfaces of the interacting surfaces of proteins were generated using PyMOL (DeLano 2002).

The number and type of non-bonding interactions between residues/atoms of the interfaces of the proteins were obtained by the in-house programme CONTACTS (R Núñez Miguel 2008, unpublished observations). In our analyses, the maximum distance considered for hydrogen bonds was $3.5 \AA$, for van der Waals interactions $4 \AA$ and for charged electrostatic interactions $7 \AA$. In the study of charge-charge interactions, a 'salt bridge' was considered when the atomic distance between the two charged atoms was $\leq 3.5 \AA$, an 'ion pair' was considered when the atomic distance was $>3.5$ and $\leq 4.5 \AA$, and those at the distance longer than $4.5 \AA$ were considered to be 'solvent-separated ion pairs'.

To study the features of the antigen-binding sites of the three TSHR human autoantibodies, a superimposition of the coordinates of the variable domains of the respective Fab fragments was carried out using the programme Discovery Studio 2.5.5 (DS 2.5.5, Accelrys, Inc.).

The amino acid hydrophobicity profiles were calculated using an in-house programme based on the Kyte \& Doolittle hydrophobicity scale (Kyte \& Doolittle 1982) with a window size of seven residues, window edge relative weight of $10 \%$ and an exponential weight variation model (Gasteiger et al. 2005). Protein surfaces were generated by PyMOL (DeLano 2002) and coloured according to the hydrophobicity profile using a yellow white green ramp. Negative profile values (hydrophilic residues) were coloured in yellow, near zero profile values were coloured in white, and positive profile values (hydrophobic residues) were coloured in green.

\section{Results}

\section{Crystal structure of K1-18 Fab}

The structure of K1-18 Fab was determined at $1.65 \AA$ resolution with a $R_{\text {work }}$ factor of $18.3 \%$ and an $R_{\text {free }}$ factor of $22.0 \%$ (Table 1). The asymmetric unit contained a single K1-18 Fab molecule with an elbow angle of $169 \cdot 1^{\circ}$. The structure of $\mathrm{K} 1-18$ is that of a standard Fab fragment with CDRs HC3 and LC3 in a central position, HC1 and LC1 positioned further out and HC2 and LC2 on the periphery. There are no sugar residues associated with the structure. Disulphide bonds are present between LC residues 23 and 88, 134 and 194, and between HC residues 22 and 92 and 142 and 208. There are 178 hydrogen bonds and salt bridges within the LC and 170 hydrogen bonds and salt bridges within the HC.

The ASA buried in the K1-18 LC-HC interface is $1607 \AA^{2}$ for the LC and $1582 \AA^{2}$ for the HC. There are $47 \mathrm{LC}$ residues and $44 \mathrm{HC}$ residues in the interface with $41 \cdot 1 \%$ polar residues and $15 \cdot 6 \%$ charged residues. A similar distribution of polar and charged residues was

Table 1 Summary of crystallographic analysis of K1-18 Fab

\begin{tabular}{|c|c|}
\hline \multicolumn{2}{|l|}{ X-ray diffraction data } \\
\hline X-ray source & Rigaku-007HF \\
\hline Wavelength $(\AA)$ & $1 \cdot 54$ \\
\hline Detector type & R-Axis IV \\
\hline Detector distance & 110 \\
\hline Temperature $\left({ }^{\circ} \mathrm{K}\right)$ & 100 \\
\hline Oscillation range per frame $\left(^{\circ}\right)$ & 0.5 \\
\hline Overall rotation $\left(^{\circ}\right)$ & 125 \\
\hline Resolution range $(\AA)$ & $30-1 \cdot 65$ \\
\hline Number of observed reflections & 258580 \\
\hline Number of unique reflections & 57696 \\
\hline Multiplicity & $4 \cdot 5$ \\
\hline $\begin{array}{l}\text { Completeness (\%; overall and last } \\
\text { shell) }\end{array}$ & $97.9(92.5)$ \\
\hline$R_{\text {merge }}(\%$; overall and last shell) & $5.5(39.2)$ \\
\hline Mean I/sigma (overall and last shell) & $13.4(2.4)$ \\
\hline Space group & $\mathrm{P} 22_{1} 2_{1}$ \\
\hline Unit cell parameters $\left(\AA{ }^{\circ}\right)$ & $\begin{array}{l}63 \cdot 074.0103 \cdot 8 \\
90 \cdot 090 \cdot 090 \cdot 0\end{array}$ \\
\hline \multicolumn{2}{|l|}{ Refinement } \\
\hline Refinement program & Refmac5 \\
\hline Resolution range $(\AA)$ & $30-1 \cdot 65$ \\
\hline Number of reflections (working/test) & $54731(2891)$ \\
\hline$R_{\text {work }}(\%)$ & $18 \cdot 3$ \\
\hline$R_{\text {free }}(\%)$ & $22 \cdot 0$ \\
\hline Protein residues modelled & 420 \\
\hline Number of protein atoms modelled & 3291 \\
\hline Number of water atoms modelled & 646 \\
\hline RMSD bond lengths $(\AA)$ & 0.012 \\
\hline RMSD bond angles $\left({ }^{\circ}\right)$ & $1 \cdot 431$ \\
\hline Mean overall $B$ value $\left(\AA^{2}\right)$ & $20 \cdot 7$ \\
\hline Mean water $B$ value $\left(A^{2}\right)$ & $33 \cdot 1$ \\
\hline Ramachandran plot favoured (\%) & $416(98 \cdot 1)$ \\
\hline Ramachandran plot allowed (\%) & $8(1.9)$ \\
\hline Ramachandran plot disallowed (\%) & $0(0.0)$ \\
\hline
\end{tabular}


observed in the M22 and K1-70 structures (41.9 and $40 \cdot 4 \%$ polar residues and $14 \cdot 1$ and $14 \cdot 6 \%$ charged residues, respectively; Sanders et al. 2011). There are nine hydrogen bonds in the interface between the two K1-18 chains.

The combining region of the K1-18 antigen-binding site (Fig. 1) is a highly irregular surface dominated by acidic patches on one side, low potential basic patches on the other side and a central positive patch. The acidic patches are centred on HC residues: D54, D56 and E64 (CDR2), and D97, D100C and D101 (CDR3).
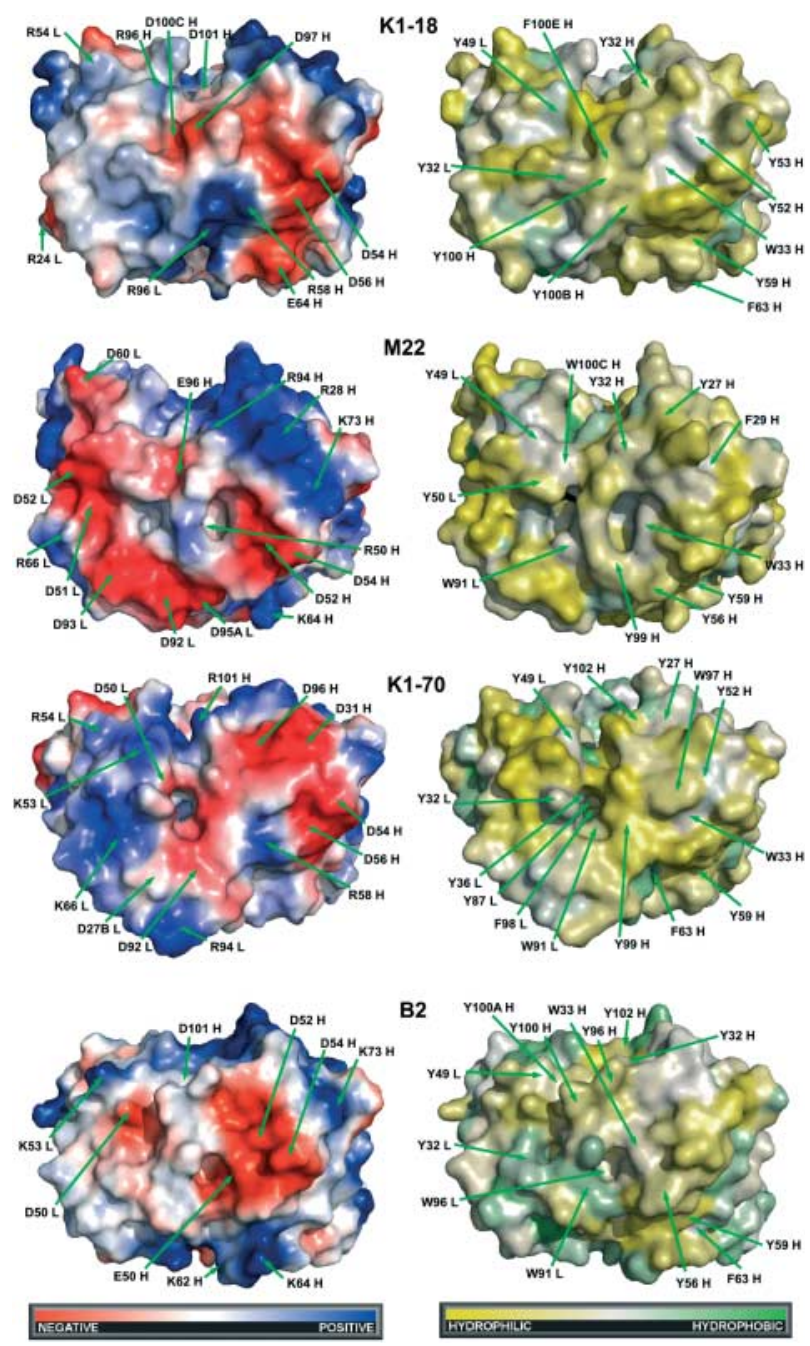

Figure 1 Electrostatic surface potentials (left panels) and hydrophobic surfaces (right panels; in PyMOL; DeLano 2002) of the antigen-binding regions of thyroid-stimulating monoclonal autoantibodies K1-18 and M22 and TSHR-blocking human monoclonal autoantibody $\mathrm{K} 1-70$ and a mouse TSHR monoclonal antibody RSR-B2. Positions of charged residues are shown on the left panels and positions of aromatic residues are shown on the right panels. Acidic patches are shown in red and basic patches in blue (left panels). Hydrophilic patches are shown in yellow and hydrophobic patches in green (right panels). Reproduced with permission from copyright holder RSR Ltd.
The low potential basic patches are centred on residues R24 (CDR1 LC), R54 (CDR2 LC) and R96 (CDR3 HC) and the central positive patch is formed by residues R96 (CDR3 LC) and R58 (CDR2 HC). The surface of $\mathrm{K} 1-18 \mathrm{Fab}$ also contains 11 aromatic residues, the majority of which are contributed from the HC (Table 2). In contrast to M22 or K1-70, there are no cavities on the surface of K1-18 (Fig. 1). Figure 1 also shows that the antigen-binding sites of the three human autoantibodies (K1-18, M22 and K1-70) are mostly hydrophilic with no hydrophobic patches on their surfaces. By contrast, the antigen-binding site of the mouse antibody (RSR-B2), which is also predominantly hydrophilic, shows some hydrophobic patches on its surface (Fig. 1).

\section{Comparison of structures of TSHR MAbs}

Analysis of the amino acid sequences of K1-18, K1-70 and M22 indicated that K1-18 has fewer charged residues in the LC CDRs than K1-70 and M22, while the K1-18 HC CDRs contain more charged residues than K1-70 and M22 (Table 2). The aromatic residues on the antigen-binding surface of K1-18 and M22 are contributed predominantly from the HCs $(9 / 11$ and 8/11 respectively), while K1-70 HC contributes 8/14 of the aromatic residues (Fig. 1 and Table 2). Although the three antibodies have a similar number of aromatic amino acids in their CDRs, M22 has fewer aliphatic amino acids in the CDRs compared with K1-18 and K1-70 (Table 2).

The K1-18 LC cysteine 91 (LC CDR3) in the structure is modified to cysteine-S-acetamide, while in the case of K1-70 and M22 there is a tryptophan at the equivalent position. However, K1-18 LC 91 cysteineS-acetamide occupies a similar space in the K1-18 Fab structure as a tryptophan in the M22 and K1-70 structures. In the M22 and K1-70 crystal structures, the LC 91 tryptophan does not make interactions with the TSHR LRD and a similar scenario is likely for K1-18 LC91.

The elbow angle of K1-18 in the crystal structure was $169 \cdot 1^{\circ}$. In the case of the K1-70 structure there were two Fab molecules in the unit cell with different elbow angles: $\mathrm{Fab} \mathrm{A}=145 \cdot 5^{\circ}$ and $\mathrm{Fab} \mathrm{B}=163 \cdot 1^{\circ}$ (Stanfield et al. 2006, Sanders et al. 2011). The elbow angle of unbound M22 ( $1 \cdot 65 \AA$ resolution) was $227 \cdot 1^{\circ}$, whereas M22 bound to the TSHR LRD ( $2.55 \AA$ resolution) had an elbow angle of $162 \cdot 0^{\circ}$ (Sanders et al. 2004, 2007a; Table 2). The elbow angle arrangements in the structure of unbound M22 resulted in M22 HC protruding farther away from the Fab structure than M22 LC (Sanders et al. 2004). By contrast, in the case of K1-70 (unbound and bound to the TSHR) and K1-18 (unbound), the relative positions of the $\mathrm{HC}$ and $\mathrm{LC}$ in the structure are more symmetrical than in the M22 structure. 
Table 2 Features of TSHR-stimulating human MAbs (M22 and K1-18), TSHR-blocking human MAb (K1-70) and TSHR-blocking mouse MAb (RSR-B2) from their crystal structures

\begin{tabular}{|c|c|c|c|c|c|c|}
\hline \multirow[b]{2}{*}{ Feature } & \multirow{2}{*}{$\frac{\text { K1-18 Fab }}{\text { Unbound }}$} & \multicolumn{2}{|l|}{ M22 Fab ${ }^{a}$} & \multicolumn{2}{|l|}{ K1-70 Fab } & \multirow{2}{*}{$\begin{array}{l}\text { RSR-B2 Fab } \\
\text { Unbound }\end{array}$} \\
\hline & & $\begin{array}{l}\text { In complex } \\
\text { with TSHR }\end{array}$ & Unbound & $\begin{array}{l}\text { In complex } \\
\text { with TSHR }\end{array}$ & Unbound & \\
\hline Crystal structure resolution $(\AA)$ & 1.65 & $2 \cdot 55$ & 1.65 & 1.90 & $2 \cdot 22$ & $3 \cdot 30$ \\
\hline Elbow angle & $169 \cdot 1$ & $162 \cdot 9$ & $227 \cdot 1$ & $166 \cdot 9$ & $\begin{array}{l}\text { Fab Ad: } 145 \cdot 5 \\
F^{d} B^{d:}: 163 \cdot 1\end{array}$ & $159 \cdot 6$ \\
\hline LC & 2 & 3 & 3 & 6 & 6 & 3 \\
\hline $\mathrm{HC}$ & 9 & 8 & 8 & 8 & 8 & 8 \\
\hline $\mathrm{LC}$ and $\mathrm{HC}$ & 11 & 11 & 11 & 14 & 14 & 11 \\
\hline \multicolumn{7}{|l|}{ Aliphatic } \\
\hline LC & 11 & 9 & 9 & 11 & 11 & 5 \\
\hline $\mathrm{LC}$ and $\mathrm{HC}$ & 11 & 10 & 10 & 12 & 12 & 8 \\
\hline
\end{tabular}

HC, heavy chain; LC, light chain; TSHR, TSH receptor.

aSanders et al. (2004, 2007a).

'Sanders et al. (2011).

'Sanders et al. (2005).

${ }^{\mathrm{d}} \mathrm{Fab} \mathrm{A}$ and Fab B denote two different Fab fragment molecules in the asymmetric unit of the crystal structure of K1-70.

A superimposition of the variable domains of unbound K1-18, K1-70 and M22 gave root mean square deviation (RMSD) values of $2 \cdot 01 \AA$ (K1-18 and $\mathrm{K} 1-70), 1 \cdot 83 \AA$ (K1-18 and M22) and $1 \cdot 02 \AA$ (K1-70 and M22) for all $\mathrm{C} \alpha$ atoms. The backbones of the combining sites of K1-70 and M22 show highly similar structures consistent with the canonical class of antibodies. The backbone of the combining site of K1-18 (IgG1/kappa) differs slightly from K1-70 (IgG1/lambda) and M22 (IgG1/lambda) due to differences in the type of the LC.

The electrostatic potential surface of $\mathrm{K} 1-18$ is characterised by a central positive patch flanked on one side by a negatively charged area and the other side by a low potential positively charged area. The negatively charged residues are contributed mostly from $\mathrm{K} 1-18 \mathrm{HC}$, while the positively charged residues are from the LC (Fig. 1). In the case of K1-70, one side of the antigen-binding site is characterised by a large negatively charged area that contains a small positive patch within, while the other side is predominantly positively charged. The negative charge is contributed mainly from $\mathrm{HC}$ residues and the positive charge from LC residues (Fig. 1). The charge distribution on the surface of M22 is opposite to that on $\mathrm{K} 1-70$; an area contributed from the HC is predominantly positively charged, whereas the area formed mainly by LC residues is predominantly negatively charged with a small positive patch contained within (Fig. 1). Overall, the electrostatic potential surfaces of the three antibodies, although different, have some characteristics in common, in particular all three combining sites contain a positive patch surrounded by a negative patch (Fig. 1).

In addition, the crystal structure of the TSHRblocking mouse antibody RSR-B2 solved at $3 \cdot 30 \AA$ (Sanders et al. 2005) was compared with the human MAbs (K1-18, M22 and K1-70). The structure of RSR-B2 is that of a standard Fab fragment with a kappa LC. It shows an elbow angle of $159 \cdot 6^{\circ}$, which is similar to the other three antibodies (Table 2). The combining region of the RSR-B2 antigen-binding site (Fig. 1) is highly irregular with a cavity in its centre similar to M22 and K1-70. The aromatic residues on the antigenbinding surface of RSR-B2 are contributed predominantly from the HC (8/11) similar to M22 and K1-18. There are only eight charged residues; two from the LC and six from the HC (Table 2). The electrostatic potential surface shows a low potential positive patch in the centre surrounded by negative patches. The acidic patches are centred on LC residue D50 (CDR2) and $\mathrm{HC}$ residues E50, D52 and D54 (CDR2), and D101 (CDR3). The low potential basic patch is centred on LC residues H34 (CDR1) and W91 (CDR3). Although the striking polarity in charge distribution on both sides of the antigen-binding surface is less evident, RSR-B2 also contains a low potential positive patch surrounded by a negative patch on its surface similar to M22, K1-18 and K1-70 (Fig. 1; Sanders et al. 2011). 
Table 3 Stimulation of cAMP production by TSH, M22 Fab and $\mathrm{K} 1-18 \mathrm{Fab}$ in $\mathrm{CHO}$ cells transfected with WT and mutated TSHR

\begin{tabular}{|c|c|c|c|}
\hline $\begin{array}{l}\text { TSHR } \\
\text { mutation }\end{array}$ & $\begin{array}{l}\text { Stimulation } \\
\text { of cAMP } \\
\text { production } \\
\text { by TSH }\end{array}$ & $\begin{array}{l}\text { Stimulation } \\
\text { of cAMP } \\
\text { production } \\
\text { by }{\mathrm{M} 22^{\mathrm{a}}}^{\text {a }}\end{array}$ & $\begin{array}{l}\text { Stimulation } \\
\text { of cAMP } \\
\text { production } \\
\text { by } \mathrm{K} 1-18\end{array}$ \\
\hline WT & +++++ & +++++ & +++++ \\
\hline R38A & ++++ & ++++ & ++++ \\
\hline D43A & +++ & +++++ & +++++ \\
\hline $\mathrm{K} 58 \mathrm{~A}$ & +++++ & +++++ & +++++ \\
\hline I60A & +++++ & +++++ & +++++ \\
\hline E61A & ++++ & +++++ & +++++ \\
\hline $\mathrm{R} 80 \mathrm{~A}$ & +++++ & 0 & +++++ \\
\hline Y82A & +++++ & +++ & +++++ \\
\hline T104A & +++++ & NT & +++++ \\
\hline $\mathrm{H} 105 \mathrm{~A}$ & +++++ & +++++ & +++++ \\
\hline E107A & +++ & 0 & +++++ \\
\hline R109A & +++++ & ++ & +++++ \\
\hline K129A & +++++ & ++ & +++++ \\
\hline F130A & +++++ & ++ & +++++ \\
\hline F134A & +++++ & +++++ & +++++ \\
\hline Y148A & +++++ & +++++ & +++++ \\
\hline D151A & +++++ & +++ & ++++ \\
\hline F153A & +++++ & ++++ & +++++ \\
\hline E157A & ++ & ++++ & 0 \\
\hline D160A & +++ & +++ & +++ \\
\hline E178A & ++++ & ++++ & ++++ \\
\hline K183A & +++++ & ++ & 0 \\
\hline Y185A & ++++ & + & 0 \\
\hline Y195A & +++++ & +++++ & +++++ \\
\hline K201A & +++++ & +++++ & +++++ \\
\hline D203A & ++++ & ++++ & +++++ \\
\hline Y206A & ++++ & ++++ & ++ \\
\hline K209A & ++++ & +++ & ++++ \\
\hline Y225A & +++++ & +++++ & +++++ \\
\hline D232A & ++++ & ++ & 0 \\
\hline Q235A & ++++ & +++++ & ++++ \\
\hline S243A & +++++ & +++++ & +++++ \\
\hline D247A & +++++ & +++++ & +++++ \\
\hline K250A & +++++ & +++++ & +++++ \\
\hline E251A & +++++ & +++++ & +++++ \\
\hline $\mathrm{R} 255 \mathrm{~A}$ & +++++ & ++ & +++++ \\
\hline T257A & +++++ & +++++ & +++++ \\
\hline W258A & +++++ & +++ & ++ \\
\hline $\mathrm{R} 274 \mathrm{~A}$ & +++++ & +++++ & ++ \\
\hline D276A & +++++ & +++++ & +++++ \\
\hline S281A & ++++ & ++++ & ++++ \\
\hline R80D & ++++ & 0 & +++++ \\
\hline H105D & ++++ & +++ & +++++ \\
\hline E107R & + & 0 & +++ \\
\hline R109D & +++ & 0 & +++ \\
\hline K129D & +++ & 0 & +++ \\
\hline D151R & +++++ & + & +++++ \\
\hline D160K & 0 & ++++ & ++ \\
\hline K183D & +++ & 0 & 0 \\
\hline K209E & +++ & + & +++++ \\
\hline R255D & +++++ & 0 & 0 \\
\hline
\end{tabular}

Relative effects of TSHR mutations were expressed as a percentage of activity observed with WT (i.e.,$+++++ 100 \%$ of WT activity; ++++ , $<100-80 \%$ of WT activity;,$+++<80-60 \%$ of WT activity; ++ , $<60-40 \%$ of WT activity;,$+<40-20 \%$ of WT activity; $0,<20 \%$ of WT activity). NT, not tested.

${ }^{a}$ The effect of TSHR mutations on the stimulation of cyclic AMP production by M22 is from Sanders et al. $(2006,2007 a, b)$.

\section{Effect of TSHR LRD mutations on K1-18 cAMP-stimulating activity}

The effects of different amino acid mutations in the TSHR extracellular domain on the ability of K1-18 to stimulate cAMP production in CHO cells expressing the mutated TSHR are shown in Table 3. Mutation of TSHR residues D43, K58, I60, E61, H105, F134, Y148, E178, Y195, K201, D203, Y225, Q235, S243, D247, K250, E251, T257, D276 and S281 to alanine showed no significant effect (compared with WT TSHR) on stimulation of cAMP production by the stimulating antibodies K1-18 or M22 (Table 3 and Fig. 2). By contrast, TSHR mutations E157A, D160K, K183A, K183D, Y185A, Y206A, D232A, R255D, W258A and R274A caused a loss or decrease of K1-18 ability to stimulate cAMP production (Table 3 and Fig. 2). The TSHR mutations R80A, R80D, Y82A, H105D, E107A, R109A, K129A, F130A, D151A, D151R, F153A, K209A, K209E and R255A had an effect on M22 cAMPstimulating activity (complete or partial reduction) but had no effect on K1-18 stimulation of cAMP (Table 3). However, six TSHR mutations-K183A, K183D, Y185A, D232A, R255D and W258A-affected both K1-18 and M22 stimulation of cAMP production to a greater extent than TSH (Table 3 ). By contrast, five TSHR mutations-R38A, E107R, R109D, K129D and D160A—all affected TSH stimulation to a similar or greater extent compared with K1-18 (Table 3 and Fig. 2), and in this case it was difficult to determine whether these amino acids were important for K1-18 binding and stimulating activity or for the correct folding of the receptor itself.

\section{Charge-charge interaction mapping of antibody binding to the TSHR LRD}

Analysis of the crystal structures of the TSHR LRD in complex with both the blocking MAb K1-70 and the stimulating MAb M22 showed that the charged patches on the surface of TSHR MAbs interact with complementary patches on the concave face of the TSHR LRD (Sanders et al. 2007a, 2011). In particular, an area with a similar electrostatic potential present on both antibody-combining sites (positive patch surrounded by a circular negative patch) interacts with a complementary charged area on the TSHR LRD (Fig. 3A and $\mathrm{B}$ ). As seen in Fig. 3A and B, the same charged areas on the TSHR LRD surface tend to form interactions with both antibodies. In addition, analysis of the electrostatic potential surface of TSH (Núñez Miguel et al. 2008) showed similarities in the distribution of charged patches compared with M22 and K1-70. Furthermore, the charge-charge interactions observed in the model of the TSH-TSHR LRD complex showed similarities to the interactions in the M22-TSHR LRD and K1-70-TSHR 


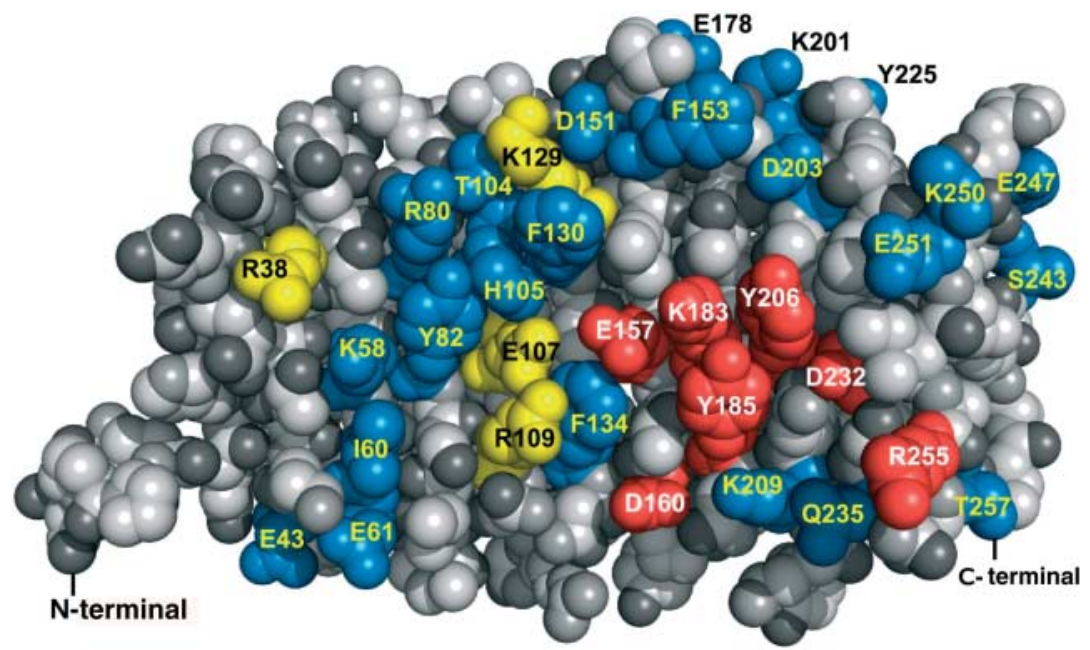

Figure 2 TSHR LRD concave surface from the crystal structure (Sanders et al. 2011) showing the residues that when mutated reduce the stimulating activity of human monoclonal autoantibody $\mathrm{K} 1-18$ (in red), the residues that when mutated do not affect the activity of $\mathrm{K} 1-18$ (in blue), and the residues for which the effect of mutation on the activity of $\mathrm{K} 1-18$ was not clear (in yellow). The $\mathrm{N}$-terminal and $\mathrm{C}$-terminal residues are marked. The mutated TSHR residues are labelled. Reproduced with permission from copyright holder RSR Ltd.

LRD complexes (Fig. 3E; Sanders et al. 2007a, 2011, Núñez Miguel et al. 2008).

In particular, several patches with a similar charge can be identified on the surface of the three ligands (M22, K1-70 and TSH) that interact with the same charged patches on the concave surface of the TSHR LRD (Fig. 4A). In addition, some patches on K1-70 and TSH are complementary to the same patches on the surface of the TSHR LRD (Fig. 4C) and some patches on M22 and TSH are complementary to the same patches on the TSHR LRD (Fig. 4B).

The observations on charge-charge interactions described earlier were used to predict the relative position of K1-18 and RSR-B2 with respect to the concave surface of TSHR LRD (Fig. 3C and D). The predicted positions were validated by the effect of TSHR amino acid mutations on cAMP activity of RSR-B2 (Sanders et al. 2006, 2010) and K1-18.

In the predicted K1-18-TSHR complex, K1-18 combines with a similar area on the TSHR LRD as M22 but is rotated by $\sim 190^{\circ}$ about an axis perpendicular to the concave surface of the TSHR LRD. In this arrangement the K1-18 LC interacts with an area on the TSHR similar to the area that interacts with M22 HC, and the K1-18 HC binds to a region on the TSHR that forms interactions with M22 LC (Fig. 3A and C). Both, M22 and K1-18 interact with almost the whole concave surface including the C-terminal region of the TSHR LRD.

In the predicted binding arrangements, RSR-B2 interacts with a similar region on the TSHR LRD as
$\mathrm{K} 1-70$ but is rotated by $\sim 150^{\circ}$ about an axis perpendicular to the concave surface of the TSHR LRD (Fig. 3D). RSR-B2 is unlikely to bind to the C-terminal region of the TSHR LRD in the predicted interactions and this is similar to the arrangements in the K1-70-TSHR LRD crystal structure.

In addition, the surface of TSH presents an equivalent positive patch surrounded by a circular negative patch to those observed on the surface of the MAbs (M22, K1-18, K1-70 and RSR-B2) that interacts with complementary charged patches on the TSHR LRD (Fig. 3E) in the model of the TSH-TSHR LRD complex (Núñez Miguel et al. 2008).

TSHR residue mutations that affect the activity of K1-18 and RSR-B2 are shown in Fig. 3C, D and Table 4 and are located within the area where the antibodies are predicted to bind. Furthermore, the TSHR residues that affect the biological activity of TSH (Table 4) are found in the area involved in predicted TSH-TSHR LRD interactions (Núñez Miguel et al. 2008).

A clear difference can be observed between thyroidstimulating and thyroid-blocking monoclonal antibodies in their interactions with the electrostatic potential patches located at the C-terminus of the TSHR LRD (Table 4). Interactions of TSHR stimulators TSH, M22 and K1-18 involve regions at the C-terminus of the TSHR LRD (Fig. 4), whereas interactions with TSHR-blocking antibodies do not (Table 4 and Fig. 4). 
A

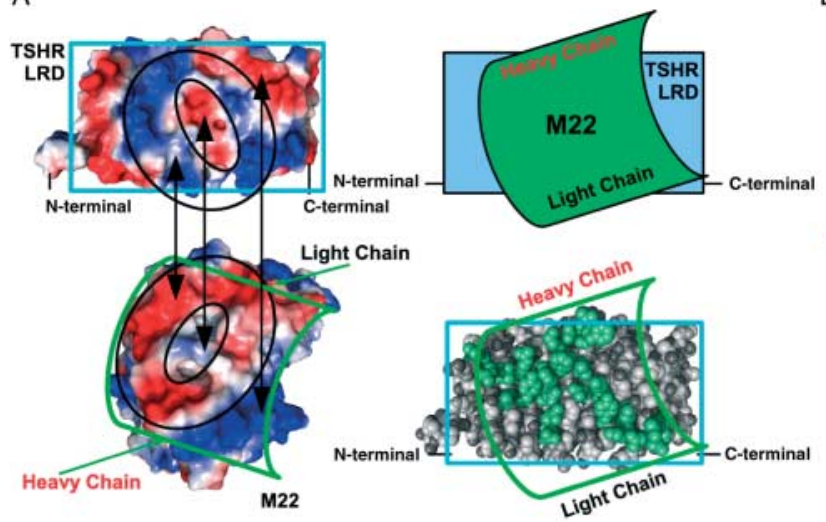

C

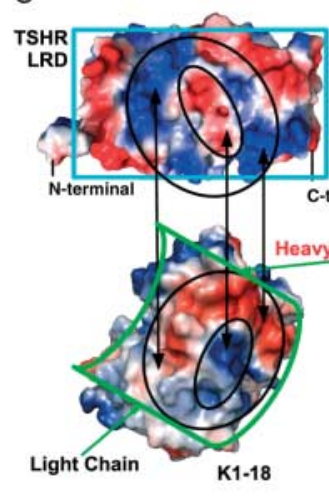

B

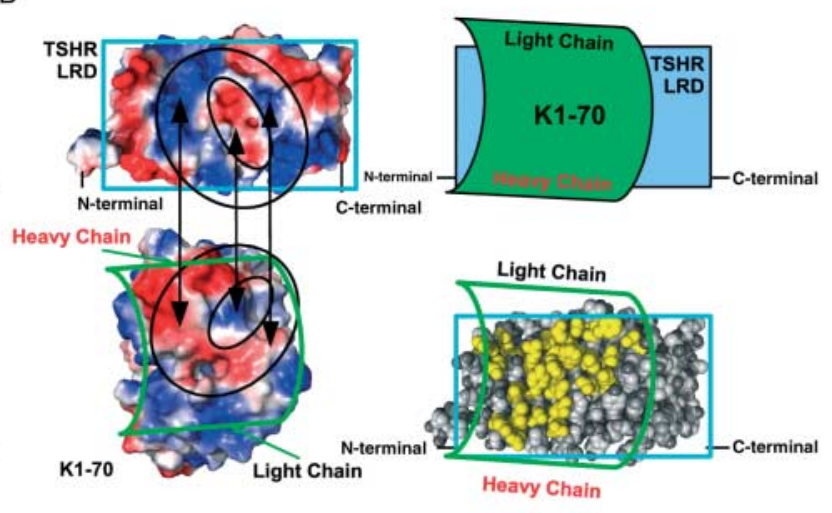

D

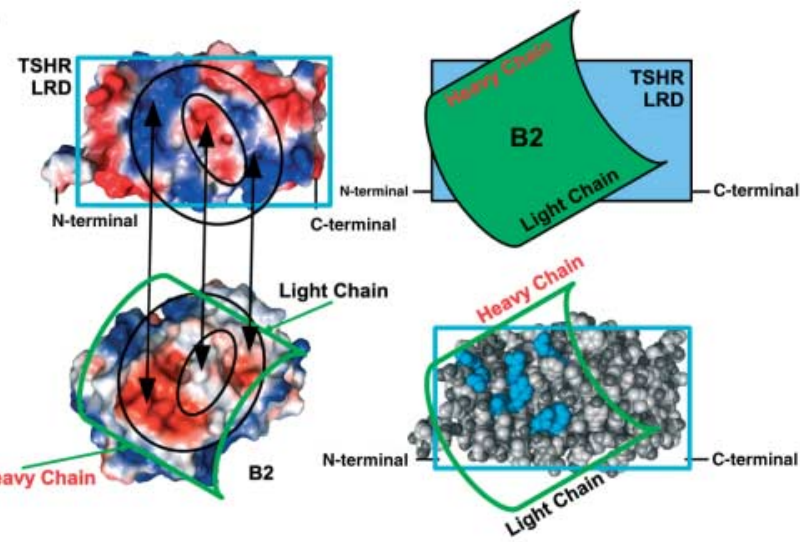

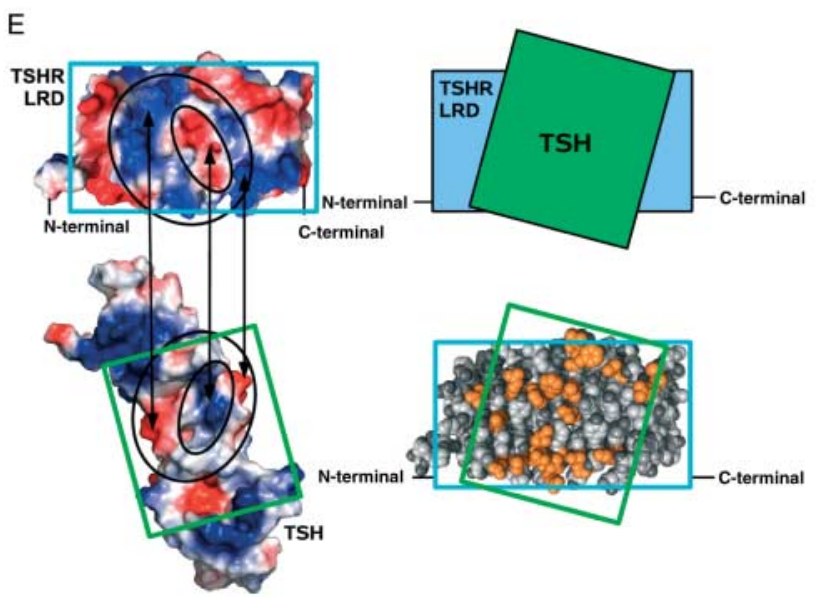

Figure 3 Ligand-receptor relative positions in the crystal structures of $(A)$ the stimulating MAb M22-TSHR LRD complex and (B) the blocking MAb K1-70-TSHR LRD complex. Prediction of binding of (C) the stimulating MAb K1-18 and (D) blocking mouse MAb RSR-B2 to the TSHR LRD. (E) TSH-TSHR LRD complex from comparative model. TSHR interacting residues with (A) M22 are in green, $(\mathrm{B}) \mathrm{K} 1-70$ in yellow and $(\mathrm{E}) \mathrm{TSH}$ in orange. TSHR mutations that affect the activity of $(\mathrm{C}) \mathrm{K} 1-18$ are in red and (D) RSR-B2 in blue. Important interacting charged patches on the electrostatic potential surfaces of the TSHR LRD, antibodies and TSH are enclosed by circles. Some interactions observed in the crystal structures of the M22-TSHR LRD and K1-70-TSHR LRD complexes, in the comparative model of the TSH-TSHR LRD complex, or predicted in the K1-18-TSHR LRD and RSR-B2-TSHR LRD complexes are shown by arrows. Antibody and TSH perimeters are in green and the TSHR LRD perimeter is in cyan. Reproduced with permission from copyright holder RSR Ltd. 

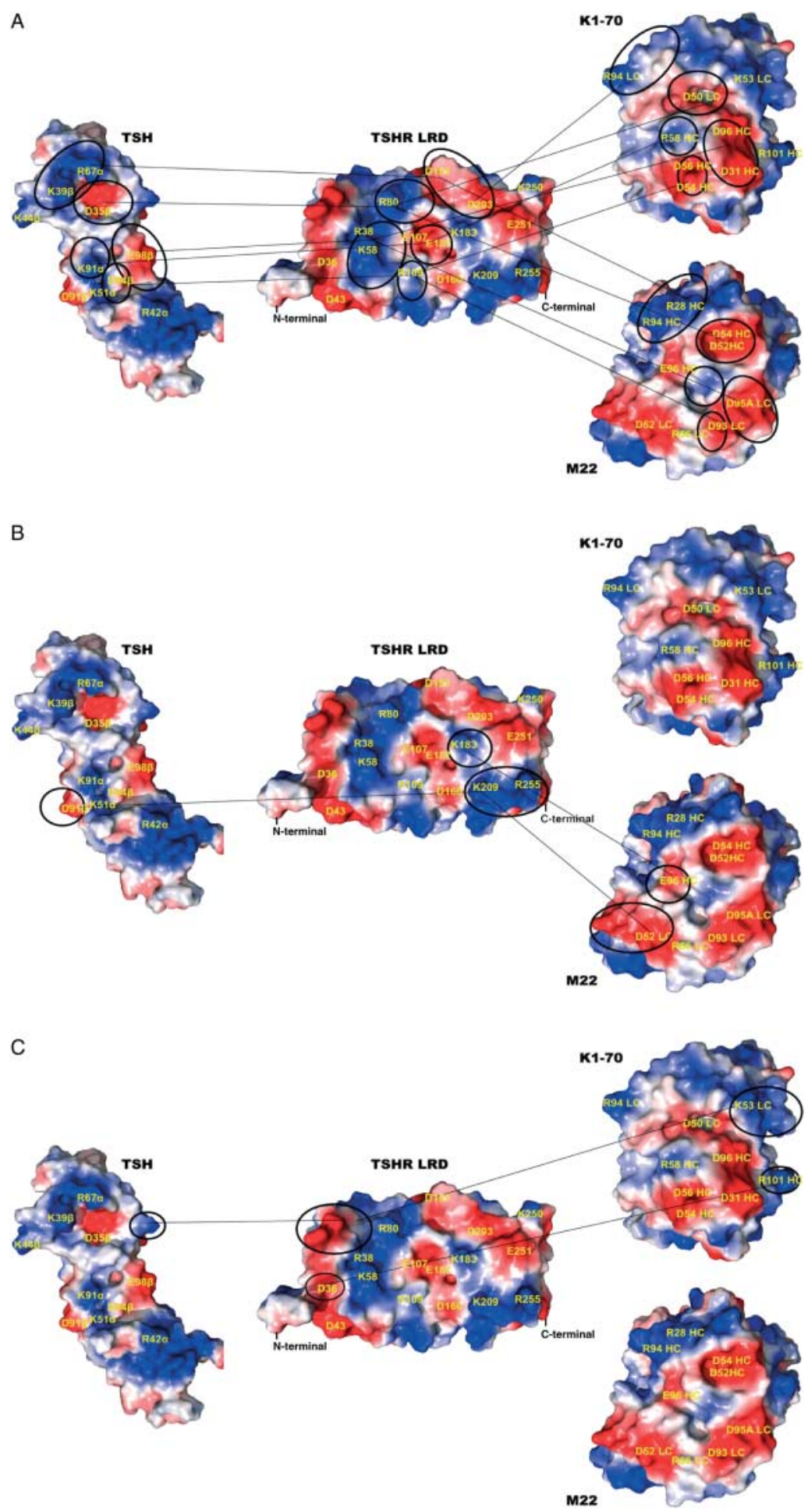

Figure 4 Electrostatic potentials of the interacting surfaces of K1-70, M22, TSH and the TSHR LRD showing some important charged residues. The N- and C-termini of the TSHR LRDs are marked. Some important interactions observed in the crystal structures of the M22-TSHR LRD and K1-70-TSHR LRD complexes, or in the comparative model of the TSH-TSHR LRD complex between the receptor and the ligands are shown by connecting lines. Negative patches are shown in red and positive in blue. Enclosed by circles are charge patches that are shared (A) by the three ligands, (B) by M22 and TSH and (C) by K1-70 and TSH. Their complementary patches on the TSHR LRD are also enclosed by circles. Reproduced with permission from copyright holder RSR Ltd. 


\section{Discussion}

This study describes the crystal structure of a new human thyroid-stimulating MAb K1-18 and a predicted model of K1-18 binding to the TSHR LRD.
Furthermore, the predicted model of TSHR LRD bound to a thyroid-blocking mouse MAb RSR-B2, for which a high-resolution crystal structure was also available (Sanders et al. 2005), is described. The crystal structures of TSHR LRD in complex with M22 and K1-

Table 4 TSHR mutations that affect the activity of K1-18 and RSR-B2, and TSHR residues having interactions with TSH in the TSHTSHR LRD comparative model; K1-70 in the K1-70-TSHR LRD crystal structure; and M22 in the M22-TSHR LRD crystal structure

\begin{tabular}{|c|c|c|c|c|}
\hline $\begin{array}{l}\text { TSHR residues that } \\
\text { interact with TSH (data } \\
\text { from the TSH-TSHR LRD } \\
\text { comparative model) }^{\mathrm{a}}\end{array}$ & $\begin{array}{l}\text { TSHR residues that } \\
\text { interact with the TSHR } \\
\text { agonist M22 (data from } \\
\text { the M22-TSHR crystal } \\
\text { structure) }\end{array}$ & $\begin{array}{l}\text { TSHR residues import- } \\
\text { ant for TSH agonistic } \\
\text { activity of } \mathrm{K} 1-18 \\
\text { (mutational studies) }\end{array}$ & $\begin{array}{l}\text { TSHR residues that } \\
\text { interact with the TSH } \\
\text { antagonist } \mathrm{K} 1-70 \text { (data } \\
\text { from the } \mathrm{K} 1-70-\mathrm{TSHR} \\
\text { crystal structure) }^{\mathrm{C}}\end{array}$ & $\begin{array}{l}\text { TSHR residues import- } \\
\text { ant for TSH antagon- } \\
\text { istic activity of MAb } \\
\text { RSR-B2 (mutational } \\
\text { studies) }\end{array}$ \\
\hline & D36 & & D36 & D36 \\
\hline \multirow[t]{2}{*}{ R38 } & R38 & & $\begin{array}{l}\text { R38 } \\
\text { K42 } \\
\text { O55 }\end{array}$ & R38 \\
\hline & T56 & & & \\
\hline K58 & K58 & & $\begin{array}{l}\mathrm{K} 58^{\mathrm{e}} \\
160^{\mathrm{e}}\end{array}$ & K58 \\
\hline E61 & & & E61 & \\
\hline R80 & $\begin{array}{l}\mathrm{R} 80^{\mathrm{e}} \\
\mathrm{Y} 82^{\mathrm{e}}\end{array}$ & & $\begin{array}{l}\text { R80 } \\
\text { Y82 } \\
\text { S84 }\end{array}$ & $\begin{array}{l}\text { R80 } \\
\text { Y82 }\end{array}$ \\
\hline \multicolumn{5}{|l|}{185} \\
\hline H105 & $\begin{array}{l}\mathrm{H} 105^{\mathrm{e}} \\
\mathrm{E} 107^{\mathrm{e}}\end{array}$ & & $\begin{array}{l}\text { T104 } \\
\text { H105 } \\
\text { E107 }\end{array}$ & \\
\hline R109 & R109 ${ }^{\mathrm{e}}$ & & R109 & R109 \\
\hline \multirow{2}{*}{\multicolumn{5}{|c|}{ T111 }} \\
\hline & \multicolumn{3}{|c|}{ R112 } & \\
\hline & $\mathrm{K} 129^{\mathrm{e}}$ & & K129 & K129 \\
\hline $\mathrm{F} 130$ & $\mathrm{~F} 130^{\mathrm{e}}$ & & F130 & F134 \\
\hline \multirow[t]{2}{*}{ N135 } & & & & \\
\hline & $\mathrm{D} 151^{\mathrm{e}}$ & & D151 & \\
\hline I152 & 1152 & & & \\
\hline F153 & $\mathrm{F} 153^{\mathrm{e}}$ & & F153 & \\
\hline 1155 & 1155 & & 1155 & \\
\hline E157 & E157 & E157 & E157 & \\
\hline \multirow{4}{*}{$\begin{array}{l}\text { P162 } \\
\text { P }\end{array}$} & & D160 & & \\
\hline & & & T181 & \\
\hline & $\mathrm{K} 183^{\mathrm{e}}$ & K183 & $\mathrm{K} 183^{\mathrm{e}}$ & \\
\hline & $Y 185^{\mathrm{e}}$ & Y185 & & \\
\hline \multirow[t]{2}{*}{ D203 } & & & D203 & \\
\hline & & Y206 & & \\
\hline \multirow[t]{3}{*}{ K209 } & $\mathrm{K} 209^{\mathrm{e}}$ & & & \\
\hline & & D232 & & \\
\hline & Q235 & & & \\
\hline \multirow{3}{*}{$\begin{array}{l}\text { K250 } \\
\text { E251 }\end{array}$} & E251 & & & \\
\hline & $\mathrm{R} 255^{\mathrm{e}}$ & R255 & & \\
\hline & & $\begin{array}{l}\text { W258 } \\
\text { R274 }\end{array}$ & & \\
\hline
\end{tabular}

aData from: Núñez Miguel et al. (2008).

bData from: Sanders et al. (2007a).

'Data from: Sanders et al. (2011).

dData from: Sanders et al. $(2006,2010)$.

${ }^{\mathrm{e}}$ Amino acids identified in the crystal structures, which when mutated affected the activity of the K1-70 or M22.

${ }^{f} \mathrm{~W} 258$ was also found to be important for M22-stimulating activity in mutation studies (Table 3); however, there was no electron density for this residue in the M22-TSHR crystal structure (Sanders et al. 2007a). 
70 allowed us to identify unique electrostatic surface potential complementarities between the TSHR and the M22 and K1-70 antibody interacting surfaces (Sanders et al. 2007a, 2011). In this study we predicted the positions of K1-18 and RSR-B2 on the TSHR LRD using charge-charge interaction mapping based on electrostatic surface potential complementarities. This strategy was validated by positioning M22 and K1-70 on the TSHR LRD using the same method and produced similar binding arrangements as those observed in the crystal structures of the respective complexes (Fig. 3; Sanders et al. 2007a, 2011).

In the predicted complex, K1-18 binds to the TSHR in a similar orientation to M22 but rotated about an axis perpendicular to the concave surface of the TSHR LRD by about $190^{\circ}$ (Fig. 3). In the predicted binding arrangements, K1-18 interacts across the whole concave surface of the TSHR LRD including the C-terminal part similar to M22 and TSH binding (Sanders et al. 2007a, Núñez Miguel et al. 2008). Furthermore, the K1-18 HC and LC appear to interact with regions of the TSHR LRD involved in interactions with TSH- $\beta$ and $-\alpha$ respectively (Núñez Miguel et al. 2008, 2009). It is likely, therefore, that K1-18 mimics binding of TSH to the TSHR as observed for M22 (Núñez Miguel et al. 2009). However, M22 LC mimics the interactions of the TSH- $\beta$ and the M22 HC mimics the interactions of TSH- $\alpha$ with the TSHR LRD (Núñez Miguel et al. 2009). Both thyroid-stimulating human MAbs M22 and K1-18 show polarity in terms of charge distribution on the surface of the antigen-binding site with one side predominantly negatively charged and the other side predominantly positively charged (Fig. 1). However, in the case of K1-18, the negative charge is contributed mostly by residues from the $\mathrm{HC}$ and the positive charge from the LC, while this is the opposite way round for M22 (Sanders et al. 2007a, Núñez Miguel et al. 2009). Therefore, both of the thyroid-stimulating human antibodies M22 and K1-18 appear to mimic TSH interactions with the TSHR LRD (albeit using different antibody chains) and it may well be that this is a feature of thyroid-stimulating human autoantibodies in general.

Based on charge-charge interaction, mapping the thyroid-blocking mouse MAb RSR-B2 is predicted to bind to a large area on the concave surface of the LRD similar to the thyroid-blocking human MAb K1-70. However the position of RSR-B2 on the TSHR LRD is rotated by $\sim 150^{\circ}$ about an axis perpendicular to the concave surface of the TSHR LRD when compared with the position of K1-70 (Fig. 3). In the predicted model RSR-B2 is not involved in interactions with the C-terminal region of the concave surface of the TSHR $\mathrm{LRD}$, and this scenario is similar to the $\mathrm{K} 1-70$ binding arrangements in the crystal structure with TSHR-260 (Sanders et al. 2011). Furthermore, analysis of the predicted interactions between RSR-B2 and the TSHR shows that RSR-B2 HC and LC do not mimic the TSH- $\alpha$ and $-\beta$ chains in their interactions with the receptor, and the same situation was observed in the case of K1-70 (Sanders et al. 2011).

The charge-charge interaction mapping method was validated by studying the effects of different TSHR mutations on the activities of both K1-18 and RSR-B2. All of the mutated TSHR residues shown to affect the stimulating activity of K1-18 or the blocking activity of RSR-B2 (Tables 3 and 4) were located within the interacting area of the predicted K1-18-TSHR and RSR-B2-TSHR complexes respectively (Fig. 3C and D). $\mathrm{K}-18$ is predicted to bind to the whole of the concave surface of the TSHR LRD. This included the C-terminal end of the LRD-containing residues identified as most important for the stimulating activity of K1-18 (E157, K183, Y185, D232, R255 or W258; Tables 3 and 4) in leucine-rich repeats (LRRs) 6-10. By contrast, the TSHR residues found to be important for RSR-B2blocking activity (K58, R80, Y82, R109 and K129; Table 4) were from the N-terminal end of the LRD; LRRs 1-5. This is similar to the binding epitope for the blocking mouse MAb $1 \mathrm{H} 7$, which was reported to interact with TSHR residues T56, K58, R80, Y82, R109, F130, G132 and F134, i.e. the TSHR N-terminus (Costagliola et al. 2004).

Although TSHR mutation R255A had no effect on the stimulating activity of K1-18, the change of charge mutation (R255D) resulted in a complete loss of K1-18 stimulating activity. In the predicted binding model, TSHR R255 would interact with a negative patch on K1-18 (Fig. 3C). Substitution of R255 with a strongly negative aspartic acid (R255D mutation) would introduce repulsion and would reduce K1-18-binding affinity to the mutated TSHR.

The importance of interactions with R255 in the C-terminus of the TSHR LRD for stimulation of cyclic AMP production has been demonstrated previously for M22, mouse TSMAbs 1-7, a hamster MAb MS-1 and patient serum TRAb (Sanders et al. 2006). The blocking activity of K1-70 was unaffected by TSHR R255D mutation while the blocking activity of RSR-B2 was increased (Sanders et al. 2006, 2011). Furthermore, TSHR stimulation by TSH was not affected by R255 mutations (Sanders et al. 2006). However, the epitopes for another two thyroid-stimulating mouse MAbs, IRI-Sab2 and IRS-Sab3 (Costagliola et al. 2004), on the TSHR were reported to involve residues T56, K58, I60, R80, Y82, S84, I85, H105, E107 and R109 (IRI-Sab2) and I60, E61, Y82, I85, E107, R109, F130, G132, F134, E157 and K183 (IRI-Sab3) at the N-terminus of the LRD. Although these binding residues overlap with our human and mouse stimulating MAb epitopes, TSHR R255 was not reported to be important for binding of IRI-Sab2 and IRA-Sab3 in FACs analysis and no cAMP 
response studies were carried out. However, IRI-Sab2 and IRI-Sab3 showed 66 and $61 \%$ binding, respectively, to the T21 Chimera (E251R/R255T mutation) relative to WT TSHR in the FACs analysis (Costagliola et al. 2004). By contrast, binding of the blocking antibody $1 \mathrm{H} 7$ was unaffected or increased at $117 \%$ (Costagliola et al. 2004). These results suggest that the stimulating MAbs IRI-Sab2 and IRI-Sab3 may also interact with $\mathrm{R} 255$ and the $\mathrm{C}$-terminal region of the receptor. Analysis of the effect of TSHR R255D changes of charge mutation on the biological activity of IRI-Sab2 and IRISab3 would be helpful to confirm the importance of R255 for TSHR stimulation by antibodies in general. An exception to this may be the mouse MAb IRI-Sab1 with a weak thyroid-stimulating activity (Costagliola et al. 2004) that was shown to bind to the N-terminus of the TSHR on the convex surface of the LRD rather than the concave surface. In addition, IRI-Sab1 showed poor inhibition of TSH or TRAb binding to the TSHR and is therefore not a representative of patient serum autoantibodies (Costagliola et al. 2004).

This study provides further evidence that the binding sites on the TSHR for stimulating and blocking mouse antibodies are extensive and overlapping. However, binding of the TSHR-blocking human MAb (K1-70) and mouse TSHR-blocking antibodies (RSR-B2 and 1H7) preferentially involves the N-terminal part of the concave surface of the LRD rather than the C-terminal part (Costagliola et al. 2004, Sanders et al. 2011).

The exact location of the binding sites for blocking autoantibodies and stimulating autoantibodies on the TSHR molecule has been controversial. Early studies with TSHR chimeras concluded that the major binding sites for thyroid-stimulating autoantibodies were located at the N-terminus of the TSHR amino acids 9-165 (Tahara et al. 1991, 1997, Kosugi et al. 1993, Kim et al. 1996, 1997, Minich \& Loos 2000, Kung et al. 2001, Minich et al. 2004), while the epitopes of blockingtype autoantibodies were more towards the TSHR C-terminus (aa 261-370; Tahara et al. 1997, Minich \& Loos 2000, Kung et al. 2001). By contrast, experimental evidence from our laboratory (Sanders et al. 1999, 2002, 2006, 2011) and other laboratories (Nagayama et al. 1991, Rapoport et al. 1998, Morgenthaler et al. 2003, 2007) suggests that the epitopes for both types of autoantibodies overlap extensively. Furthermore, analysis of the crystal structures of the TSHR complexed with a blocking MAb K1-70 and a stimulating MAb M22 clearly shows that the binding sites of the two antibodies overlap considerably on TSHR260 (aa 22-260; Sanders et al. 2007a, 2011). The current study predicts that the thyroid-stimulating human $\mathrm{MAb}$ K1-18 and the thyroid-blocking mouse MAb RSR-B2 also bind to TSHR260. This is in contrast to the previously reported TSHR epitope aa 261-370 important for blocking antibodies (Tahara et al. 1997, Minich
\& Loos 2000, Kung et al. 2001, Loos et al. 2007), which is missing entirely from the TSHR-260 construct. Furthermore, K1-70, K1-18 and M22 bind strongly to TSHR260 in a bridging ELISA (Rees Smith et al. 2009). In addition, over 50 patient serum TSHR autoantibodies interacted with TSHR260 (Rees Smith et al. 2009) including five sera with blocking activity and five sera with stimulating activity. However, a report (Schwarz-Lauer et al. 2002) in which the TSHR-blocking activity of one patient serum could not be absorbed by purified TSHR289 (aa 22-289), even though the blocking antibodies in a different serum and all the stimulating antibodies studied were absorbed, could indicate that occasional patient autoantibodies with blocking activity might bind outside the TSHR260 region.

It is possible that activation of the TSHR may involve changes in the relative positions of the TSHR LRD, the cleavage domain (CD) and/or the extracellular loops of the transmembrane domain (TMD) in the TSHR molecule (Szkudlinski et al. 2002, Vlaeminck-Guillem et al. 2002, Moyle et al. 2004, Kleinau et al. 2008, Mueller et al. 2008, Kleinau \& Krause 2009). Interactions of antibodies with the C-terminal region of the TSHR LRD may trigger modification of the relative position of the three domains leading to receptor activation. Activation of the receptor by TSH is also likely to involve modification of the relative position of the three domains, although this may be achieved by a different mechanism not requiring interactions with the C-terminal region around TSHR R255. Experimental studies demonstrated that substitutions of $\alpha \mathrm{TSH}$ residues T11, Q13, P16 and Q20 with lysine substantially increased TSHR-binding affinity and bioactivity (Szkudlinski et al. 1996). These $\alpha \mathrm{TSH}$ residues do not interact with the TSHR LRD in our model of the TSH-TSHR LRD complex and the equivalent $\alpha \mathrm{FSH}$ residues do not interact with the FSHR LRD in the crystal structure of the FSH-FSHR LRD complex (Fan \& Hendrickson 2005). Consequently, it is possible that aTSH T11, Q13, P16 and Q20 interact with other domains of the receptor (Núñez Miguel et al. 2004, 2005, 2008, Mizutori et al. 2008, Mueller et al. 2008, Chen et al. 2010). Three steps leading to TSHR activation were suggested by Kleinau \& Krause (2009) including hormone binding, intramolecular signal transduction within the TSHR extracellular regions and finally transmission to the transmembrane region. In this scenario, specific multiple contacts between the hormone and the TSHR LRD would lead to selective hormone binding. The hormone would also contact the TSHR CD, and the TSHR LRD together with the CD would form a large hormone-binding pocket. This is in agreement with several studies that have shown that the TSHR CD is likely to have an important role as a signalling specificity domain (Mizutori et al. 2008, Mueller et al. 2008, 2009, Hamidi et al. 2011). 
In the case of the $\mathrm{LH}$ receptor, a sequence T250-Q268 (equivalent to D276-G294 of the TSHR CD) was shown to specifically interact with hCG, preferentially hCG $\alpha$. A close relationship between hCG and the LH receptor extracellular domain equivalent to TSHR CD and the extracellular loop 2 has been suggested (Zeng et al. 2001). By contrast, however, it has been proposed that the extracellular loops 1 and 3 of the TMD of the FSHR have features of secondary binding sites and might interact with the ectodomain-bound $\alpha$ FSH (Dupakuntla \& Mahale 2010).

The available crystal structures of the TSHR in complex with M22 and K-70 provide valuable insight into how a stimulating and a blocking antibody bind to the TSHR and, together with extensive experimental studies, suggest that these arrangements reflect binding of TSHR antibodies in general (Sanders $e t$ al. 2006, 2007a,b, 2010, 2011). In the absence of further crystal structures of the TSHR in complex with other antibodies, we have used charge-charge interaction mapping methodology to predict binding of a new thyroid-stimulating human MAb K1-18 and a thyroidblocking mouse MAb RSR-B2 with the TSHR. The predicted binding arrangements were validated by the effects of the TSHR amino acid mutations on the biological activity of the MAbs, and the binding arrangements of the TSHR LRD with two stimulating (M22 and K1-18) and two blocking MAbs (K1-70 and RSR-B2) were compared. The limitation of this study is that it is based on a combination of evidence from high-resolution crystal structures (Sanders et al. $2007 a$, 2011), a comparative model (Núñez Miguel et al. 2008), mutational analysis and more robust chargecharge interaction mapping. However, these studies showed that the binding sites for the TSHR antibodies with different biological activities overlap on the concave surface of the TSHR; however, stimulating antibodies show interactions with both the $\mathrm{N}$ - and C-terminus of the TSHR LRD while the blocking antibodies do not interact with the C-terminus. Whether this is the case for all TSHR-stimulating and -blocking antibodies (human and raised in animals) in general should be clarified with more TSHR MAbs as they may become available in the future. Understanding these interactions at the molecular level is likely to be useful in designing small molecules that would interfere with stimulating or blocking antibodies binding to the TSHR. Furthermore, this type of understanding may be helpful in future studies on how ligand-binding triggers TSHR activation.

\section{Declaration of interest}

All authors are employees of RSR Ltd. RSR Ltd is a developer of medical diagnostics including kits for measuring TSH receptor autoantibodies.

\section{Funding}

The work was funded by RSR Ltd.

\section{Acknowledgements}

We acknowledge the assistance of Carol James in preparation of the manuscript.

\section{References}

Bolton J, Sanders J, Oda Y, Chapman C, Konno R, Furmaniak J \& Rees Smith B 1999 Measurement of thyroid-stimulating hormone receptor autoantibodies by ELISA. Clinical Chemistry $\mathbf{4 5}$ $2285-2287$.

Chen C-R, McLachlan SM \& Rapoport B 2010 Thyrotropin (TSH) receptor residue E251 in the extracellular leucine-rich repeat domain is critical for linking TSH binding to receptor activation. Endocrinology 151 1940-1947. (doi:10.1210/en.2009-1430)

Collaborative Computational project, number 41994 The CCP4 Suite: Programmes for protein crystallography. Acta Crystallographica D50 760-763. (doi:10.1107/S0907444994003112)

Costagliola S, Bonomi M, Morgenthaler NG, Van Durme J, Panneels V, Refetoff S \& Vassart G 2004 Delineation of the discontinuousconformational epitope of a monoclonal antibody displaying full in vitro and in vivo thyrotropin activity. Molecular Endocrinology 18 3020-3034. (doi:10.1210/me.2004-0231)

DeLano WL 2002 The PyMOL Molecular Graphics System. San Carlos, CA, USA: DeLano Scientific (http://sourceforge.net/projects/pymol).

Dupakuntla M \& Mahale SD 2010 Accessibility of the extracellular loops of follicle stimulating hormone receptor and their role in hormone-receptor interaction. Molecular and Cellular Endocrinology 315 131-137. (doi:10.1016/j.mce.2009.10.002)

Emsley P, Lohkamp B, Scott W \& Cowtan K 2010 Features and developments of COOT. Acta Crystallographica D66 486-501. (doi: $10.1107 /$ S0907444910007493)

Evans M, Sanders J, Tagami T, Sanders P, Young S, Roberts E, Wilmot J, Hu X, Kabelis K, Clark J et al. 2010 Monoclonal autoantibodies to the TSH receptor, one with stimulating activity and one with blocking activity, obtained from the same blood sample. Clinical Endocrinology 73 404-412. (doi:10.1111/ j.1365-2265.2010.03831.x)

Fan QR \& Hendrickson WA 2005 Structure of human follicle stimulating hormone in complex with its receptor. Nature 433 269-277. (doi:10.1038/nature03206)

Gasteiger E, Hoogland C, Gattiker A, Duvaud S, Wilkins MR, Appel RD \& Bairoch A 2005 Protein identification and analysis tools on the ExPASy server. In The Proteomics Protocols Handbook, pp 581-582. Ed John M Walker. New Jersey: Humana Press.

Hamidi S, Chen CR, Mizutori-Sasai Y, McLachlan SM \& Rapoport B 2011 Relationship between thyrotropin receptor hinge region proteolytic posttranslational modification and receptor physiological function. Molecular Endocrinology 25 184-194. (doi:10.1210/me. 2010-0401)

Jones S \& Thornton JM 1996 Principles of protein-protein interactions. PNAS 93 13-20. (doi:10.1073/pnas.93.1.13)

Kabat E, Perry H, Wu T, Gottesman K \& Foeller C 1991 Sequences of Proteins of Immunological Interest, 5 th edn. Bethesda, MD: US Public Health Service.

Kim WB, Cho BY, Park HY, Lee HK, Kohn LD, Tahara K \& Koh CS 1996 Epitopes for thyroid-stimulating antibodies in Graves' sera: a possible link of heterogeneity to differences in response to antithyroid drug treatment. Journal of Clinical Endocrinology and Metabolism 81 1758-1767. (doi:10.1210/jc.81.5.1758) 
Kim WB, Chung HK, Lee HK, Kohn LD, Tahara K \& Cho BY 1997 Changes in epitopes for thyroid-stimulating antibodies in Graves' disease sera during treatment of hyperthyroidism: therapeutic implications. Journal of Clinical Endocrinology and Metabolism 82 1953-1959. (doi:10.1210/jc.82.6.1953)

Kleinau G \& Krause G 2009 Thyrotropin and homologous glycoprotein hormone receptors: structural and functional aspects of extracellular signaling mechanisms. Endocrine Reviews 30 133-151. (doi:10.1210/er.2008-0044)

Kleinau G, Jaeschke H, Mueller S, Raaka BM, Neumann S, Paschke R \& Krause G 2008 Evidence for cooperative signal triggering at the extracellular loops of the TSH receptor. FASEB Journal 22 2798-2808. (doi:10.1096/fj.07-104711)

Kosugi S, Ban T \& Kohn LD 1993 Identification of thyroid-stimulating antibody-specific interaction sites in the $\mathrm{N}$-terminal region of the thyrotropin receptor. Molecular Endocrinology 7 114-130. (doi:10.1210/me.7.1.114)

Kung AW, Lau KS \& Kohn LD 2001 Epitope mapping of TSH receptor-blocking antibodies in Graves' disease that appear during pregnancy. Journal of Clinical Endocrinology and Metabolism 86 3647-3653. (doi:10.1210/jc.86.8.3647)

Kyte J \& Doolittle RF 1982 A simple method for displaying the hydropathic character of a protein. Journal of Molecular Biology 157 105-132. (doi:10.1016/0022-2836(82)90515-0)

Laskowski RA, MacArthur MW, Moss DS \& Thornton JM 1993 PROCHECK - a program to check the stereochemical quality of protein structures. Journal of Applied Crystallography 26 283-291. (doi:10.1107/S0021889892009944)

Loos U, Franz C, Minich WB \& Büsselmann I 2007 Direct assay of TSH receptor autoantibodies causing Graves' disease correlates with the clinical diagnosis closer than assays based on TSH displacement. Hormone Research 68 63. (doi: 10.1159/000107670)

McLachlan SM \& Rapoport B 1996 Monoclonal human autoantibodies to the TSH receptor - the holy grail and why are we looking for it? Journal of Clinical Endocrinology and Metabolism 81 3152-3154. (doi:10.1210/jc.81.9.3152)

Minich WB \& Loos U 2000 Detection of functionally different types of pathological autoantibodies against thyrotropin receptor in Graves' patients sera by luminescent immunoprecipitation analysis. Experimental and Clinical Endocrinology E Diabetes 108 110-119. (doi:10.1055/s-2000-5804)

Minich WB, Lenzner C, Bergmann A \& Morgenthaler NG 2004 A coated tube assay for the detection of blocking thyrotropin receptor autoantibodies. Journal of Clinical Endocrinology and Metabolism 89 352-356. (doi:10.1210/jc.2003-030823)

Mizutori Y, Chen C-R, McLachlan SM \& Rapoport B 2008 The thyrotropin receptor hinge region is not simply a scaffold for the leucine-rich domain but contributes to ligand binding and signal transduction. Molecular Endocrinology 22 1171-1182. (doi:10.1210/ me.2007-0407)

Morgenthaler NG, Minich WB, Willnich M, Bogusch T, Hollidt JM, Weglohner W, Lenzner C \& Bergmann A 2003 Affinity purification and diagnostic use of TSH receptor autoantibodies from human serum. Molecular and Cellular Endocrinology 212 73-79. (doi:10.1016/ j.mce.2003.09.018)

Morgenthaler NG, Ho SC \& Minich WB 2007 Stimulating and blocking thyroid stimulating hormone (TSH) receptor autoantibodies from patients with Graves' disease and autoimmune hypothyroidism have very similar concentration, TSH receptor affinity, and binding sites. Journal of Clinical Endocrinology and Metabolism 92 1058-1065. (doi:10.1210/jc.2006-2213)

Moyle WR, Xing Y, Lin W, Cao D, Myers RV, Kerrigan JE \& Bernard MP 2004 Model of glycoprotein hormone receptor ligand binding and signaling. Journal of Biological Chemistry 279 44442-44459. (doi:10.1074/jbc.M406948200)

Mueller S, Kleinau G, Jaeschke H, Paschke R \& Krause G 2008 Extended hormone binding site of the human thyroid stimulating hormone receptor: distinctive acidic residues in the hinge region are involved in bovine thyroid stimulating hormone binding and receptor activation. Journal of Biological Chemistry 283 18048-18055. (doi:10.1074/jbc.M800449200)

Mueller S, Jaeschke H, Günther R \& Paschke R 2009 The hinge region: an important receptor component for GPHR function. Trends in Endocrinology and Metabolism 21 111-122. (doi:10.1016/j.tem.2009. 09.001)

Nagayama Y, Wadsworth HL, Russo D, Chazenbalk GD \& Rapoport B 1991 Binding domains of stimulatory and inhibitory thyrotropin (TSH) receptor autoantibodies determined with chimeric TSH-lutropin/chorionic gonadotropin receptors. Journal of Clinical Investigation 88 336-340. (doi:10.1172/JCI115297)

Núñez Miguel R, Sanders J, Jeffreys J, Depraetere H, Evans M, Richards T, Blundell TL, Rees Smith B \& Furmaniak J 2004 Analysis of the thyrotropin receptor-thyrotropin interaction by comparative modeling. Thyroid 14 991-1011. (doi:10.1089/thy. 2004.14.991)

Núñez Miguel R, Sanders J, Blundell TL, Rees Smith B \& Furmaniak J 2005 Comparative modeling of the thyrotropin receptor. Thyroid $\mathbf{1 5}$ 746-747. (doi:10.1089/thy.2005.15.746)

Núñez Miguel R, Sanders J, Chirgadze DY, Blundell TL, Furmaniak J \& Rees Smith B 2008 FSH and TSH binding to their respective receptors - similarities, differences and implications for glycoprotein hormone specificity. Journal of Molecular Endocrinology 41 145-164. (doi:10.1677/JME-08-0040)

Núñez Miguel R, Sanders J, Chirgadze DY, Furmaniak J \& Rees Smith B 2009 Thyroid stimulating autoantibody M22 mimics TSH in its binding to the TSH receptor leucine rich domain: a comparative structural study of protein-protein interactions. Journal of Molecular Endocrinology 42 381-395. (doi:10.1677/JME-08-0152)

Rapoport B, Chazenbalk GD, Jaume JC \& McLachlan SM 1998 The thyrotropin (TSH) receptor: interaction with TSH and autoantibodies. Endocrine Reviews 19 673-716. (doi:10.1210/er.19.6.673)

Rees Smith B, Sanders J, Evans M, Tagami T \& Furmaniak J 2009 TSH receptor-autoantibody interactions. Hormone and Metabolic Research 41 448-455. (doi:10.1055/s-0029-1220913)

Sanders J, Oda Y, Roberts S, Kiddie A, Richards T, Bolton J, McGrath V, Walters S, Jaskólski D, Furmaniak J et al. 1999 The interaction of TSH receptor autoantibodies with 125I-labelled TSH receptor. Journal of Clinical Endocrinology and Metabolism 84 3797-3802. (doi:10.1210/jc.84.10.3797)

Sanders J, Jeffreys J, Depraetere H, Richards T, Evans M, Kiddie A, Brereton K, Groenen M, Oda Y, Furmaniak J et al. 2002 Thyroid stimulating monoclonal antibodies. Thyroid 12 1043-1050. (doi:10.1089/105072502321085135)

Sanders J, Jeffreys J, Depraetere H, Evans M, Richards T, Kiddie A, Brereton K, Premawardhana LDKE, Chirgadze DY, Núñez Miguel R et al. 2004 Characteristics of a human monoclonal autoantibody to the thyrotropin receptor: sequence structure and function. Thyroid 14 560-570. (doi:10.1089/1050725041692918)

Sanders J, Allen F, Jeffreys J, Bolton J, Richards T, Depraetere H, Nakatake N, Evans M, Kiddie A, Premawardhana LDKE et al. 2005 Characteristics of a monoclonal antibody to the thyrotropin receptor that acts as a powerful thyroid-stimulating autoantibody antagonist. Thyroid 15 672-682. (doi:10.1089/thy.2005.15.672)

Sanders J, Bolton J, Sanders P, Jeffreys J, Nakatake N, Richards T, Evans M, Kiddie A, Summerhayes S, Roberts E et al. 2006 Effects of TSH receptor mutations on binding and biological activity of monoclonal antibodies and TSH. Thyroid 16 1195-1206. (doi:10.1089/thy.2006.16.1195)

Sanders J, Chirgadze DY, Sanders P, Baker S, Sullivan A, Bhardwaja A, Bolton J, Reeve M, Nakatake N, Evans M et al. 2007a Crystal structure of the TSH receptor in complex with a thyroid stimulating autoantibody. Thyroid 17 395-410. (doi:10.1089/ thy.2007.0034)

Sanders J, Núñez Miguel R, Bolton J, Bhardwaja A, Sanders P, Nakatake N, Evans M, Blundell TL, Furmaniak J \& Rees Smith B 
$2007 b$ Molecular interactions between the TSH receptor and a thyroid stimulating monoclonal autoantibody. Thyroid 17 699-706. (doi:10.1089/thy.2007.0041)

Sanders J, Núñez Miguel R, Furmaniak J \& Rees Smith B 2010 TSH receptor monoclonal antibodies with agonist, antagonist, and inverse agonist activity. Methods in Enzymology 485 393-420. (doi:10. 1016/B978-0-12-381296-4.00022-1)

Sanders P, Young S, Sanders J, Kabelis K, Baker S, Sullivan A, Evans M, ClarkJ, Wilmot J, Hu X et al. 2011 Crystal structure of the TSH receptor (TSHR) bound to a blocking-type TSHR autoantibody. Journal of Molecular Endocrinology 46 81-99. (doi:10.1530/JME-10-0127)

Schwarz-Lauer L, Chazenbalk GD, Mclachlan SM, Ochi Y, Nagayama Y \& Rapoport B 2002 Evidence for a simplified view of autoantibody interactions with the thyrotropin receptor. Thyroid 12 115-120. (doi:10.1089/105072502753522347)

Stanfield RL, Zemla A, Wilson IA \& Rupp B 2006 Antibody elbow angles are influenced by their light chain class. Journal of Molecular Biology 357 1566-1574. (doi:10.1016/j.jmb.2006.01.023)

Szkudlinski MW, Teh NG, Grossmann M, Tropea JE \& Weintraub BD 1996 Engineering human glycoprotein hormone superactive analogues. Nature Biotechnology 14 1257-1263. (doi:10.1038/ nbt1096-1257)

Szkudlinski MW, Fremont V, Ronin C \& Weintraub BD 2002 Thyroidstimulating hormone and thyroid-stimulating hormone receptor structure-function relationships. Physiological Reviews 82 473-502. (doi:10.1152/physrev.00031.2001)
Tahara K, Ban T, Minegishi T \& Kohn LD 1991 Immunoglobulins from Graves' disease patients interact with different sites on TSH receptor/LH-CG receptor chimeras than either TSH or immunoglobulins from idiopathic myxedema patients. Biochemical and Biophysical Research Communications 179 70-77. (doi:10.1016/0006291X(91)91335-A)

Tahara K, Ishikawa N, Yamamoto K, Hirai A, Ito K, Tamura Y, Yoshida S, Saito Y \& Kohn LD 1997 Epitopes for thyroid stimulating and blocking autoantibodies on the extracellular domain of the human thyrotropin receptor. Thyroid 7 867-877. (doi:10.1089/thy.1997.7.867)

Vlaeminck-Guillem V, Ho SC, Rodien P, Vassart G \& Costagliola S 2002 Activation of the cAMP pathway by the TSH receptor involves switching of the ectodomain from a tethered inverse agonist to an agonist. Molecular Endocrinology 16 736-746. (doi:10.1210/me.16.4.736)

Zeng H, Phang T, Song YS, Ji I \& Ji TH 2001 The role of the hinge region of the luteinizing hormone receptor in hormone interaction and signal generation. Journal of Biological Chemistry 276 3451-3458. (doi:10.1074/jbc.M007488200)

Received in final form 22 May 2012

Accepted 24 July 2012

Made available online as an Accepted Preprint 24 July 2012 